\title{
Vertical Integration of Engineer Education in K-12 Rural Schools
}

\section{Dr. Gary R. Mayer, Southern Illinois University Edwardsville}

Dr. Gary Mayer is an assistant professor in the Department of Computer Science at Southern Illinois University Edwardsville. His research emphasizes formal model composition between disparate subsystem models. Other research interests include robotics and artificial intelligence. Dr. Mayer regularly teaches courses in software engineering, robotics, and modeling and simulation. He is a Botball Educational Robotics Program instructor and coordinator for the Greater St Louis Region. Dr. Mayer was awarded his Ph.D. in Computer Science from Arizona State University in 2009, his M.Sc. in Computer Science from Southern Illinois University Edwardsville in 2004, and his B.S. in Mechanical Engineering with Aerospace Interest from Worcester Polytechnic Institute in 1992. He has ten years experience in program management and aeronautical engineering as an active duty U.S. Air Force officer.

\section{Dr. Allison Jane Fahsl, Southern Illinois University Edwardsville}

Dr. Allison J. Fahsl is an Associate Professor in the Department of Special Education and Communication Disorders at Southern Illinois University Edwardsville. She has over 20 years of teaching experience in a variety of areas and levels including elementary, special education and higher education. Areas of interest and expertise include accommodations for students with disabilities, differentiated instruction, math and science instruction, and action research. Dr. Fahsl received her Ph.D. from Oklahoma State University in 2001.

\section{Dr. Stephen McCaire Marlette, Southern Illinois University Edwardsville}

Dr. Stephen Marlette is an associate professor in the Department of Curriculum \& Instruction at Southern Illinois University Edwardsville. He has research interests that include the implementation and use of science education standards. His primary undergraduate teaching assignment is elementary and middle school science methods. At the graduate level he has helped design and teaches in a Masters of Arts program designed for second career STEM professionals. He also teaches a variety of courses to assist classroom teachers with curriculum development, analyzing their instruction and conducting action research. Dr. Marlette was awarded his Ph.D. from Kansas State University in 2002. During his professional career he has taught both middle and high school science, worked in professional development schools, and provided teacher professional development at all grade levels (K-12). He regularly collaborates with STEM faculty on various projects and grants to improve K-12 STEM learning. He currently is serving as a faculty fellow in the SIUE Center for STEM Research, Education and Outreach.

\section{Georgia Bracey, Southern Illinois University, Edwardsville}

Georgia Bracey is a research associate in the Center for STEM Research, Education, and Outreach at Southern Illinois University Edwardsville. She has a B.A. in Elementary Education and spent thirteen years teaching in public schools. In 2009, she received an M.S. in Physics and is currently a doctoral student in Education at the University of Missouri-St. Louis. Her research interests include physics/astronomy education, citizen science, and the integration of technology in teaching and learning. 


\section{Vertical Integration of Engineering Education in K-12 Rural Schools}

introduction

Engineering design and technology related concepts have historical relevance in standards based science education reform ${ }^{1}$. The release of the newly articulated framework for K-12 science education written by the Committee on Conceptual Framework for New Science Education Standards ${ }^{2}$ has created a renewed sense of importance in this area. Of particular interest to the authors is the emphasis on engineering design and how it may be integrated into K-12 curricula. A funded research effort was therefore implemented to provide professional development to teachers in rural districts, promoting the integration of engineering design into their curriculum. The primary intent was for teachers to make use of the process as a tool for helping students to better learn the current curricula, rather than instruct the students in engineering or engineering design itself.

This rural engineering education initiative is a partnership between five Midwestern rural school districts, a local university, and a regional office of education. The project activities are designed to promote and support the integration of engineering design and technology related concepts into the rural classrooms associated with the partnership. Specifically, the project goals include:

1. Increasing rural K-12 teachers' understanding of engineering design, the design process, and technology concepts,

2. The vertical integration of engineering design and technology in the curriculum across $\mathrm{K}-12$ grade levels, and

3. Increasing teacher support, collaboration, and collegiality related to science instruction.

The content focus of the initiative is in line with education reform documents that articulate K-12 science content.

As discussed in the General Approach section, the total effort encompassed two years with two groups of teachers. This paper focuses on the 26 teachers that participated in the first year. The workshop participants for the first year were all public school teachers representing a variety of grade levels, with the majority from the elementary grades: four teachers at grades K-2, eight at grades 3-5, and six at grades 6-8. Also attending were five high school teachers, and three special education teachers who spanned grades K-12. Although some of the K-8 teachers expressed an interest in science, few had teaching certifications in science and most felt that this was an area where they needed support and needed to improve. The high school teachers had a range of math and science-related backgrounds (e.g., biology and chemistry) but were unfamiliar with teaching using an engineering design process. 
general approach

The overall project is a two year work-in-progress that is nearing completion. It has a two-prong focus: (1) a summer institute focused on addressing teacher content knowledge, and (2) the creation of professional learning communities to develop and study the implementation of the engineering design and technology-related lessons during a school year follow-up. The summer institute included such things as design challenge immersion experiences ${ }^{3}$, a LEGO ${ }^{\circledR}$ robotics challenge, and two field trips to provide direct contact with professionals in various engineering careers and contexts. The school year follow-up activities utilized were based on components of Japanese Lesson Study ${ }^{4}$. The summer institute along with the school year follow-up activities forms one professional development cycle that was repeated twice during the life of the project. The first-year cycle focused primarily on grades K-5 and the second-year cycle focused primarily on grades 6-12. In both cycles, several teachers outside the primary grade levels for that year were included in the participant pool in order to facilitate vertical integration of educational activities. In other words, it provided an opportunity for elementary, middle, and high school teachers to discuss integration and gaps between their respective curricula along the grade-level continuum.

The effort and data analysis for the first-year cycle is complete. The second-year cycle effort has recently been completed and only preliminary data is available. As such, the remainder of the paper will discuss only the first year's efforts and results.

engineering design process

The purpose of the summer workshop was to expose the teacher-participants to a curriculum that emphasized 21st Century Skills such as creativity, problem solving, and communication ${ }^{5}$. The participants (teachers) were to then carry applicable components of this curriculum back to their own classrooms. Engineering design is the framework upon which this curriculum was built. The reason for this is that the purpose of engineering as a profession is to tackle large, complex problems and there is a systematic approach for doing $\operatorname{such}^{6-8}$. As part of the project, the intent was to take the essence of the engineering design process and provide it as a tool to support teachers in enabling more open-minded, creative problem solving in their classrooms. Simplification was necessary to prepare the teachers to be able to teach their students using engineering design concepts. Our goal was not to make either the teachers or their students engineers; it was to provide a structured approach for the teachers to use in their classrooms, so that students could work at devising solutions to open-ended problems - those without explicit right or wrong answers. 
While engineering may have many different fields, as a profession its purpose is to devise solutions to complex problems in order to benefit society. These complex problems do not have a unique solution. There are many solutions and an engineer goes through a systematic process in order to choose one. This process, typically called the engineering design process, is applicable to many complex problems, whether or not the person trying to solve them is formally an engineer $^{6-8}$. To capture and present the essence of the engineering design process, a modified version of the approach presented in Engineering is Elementary ${ }^{\circledR 9}$ was used (see Figure 1).

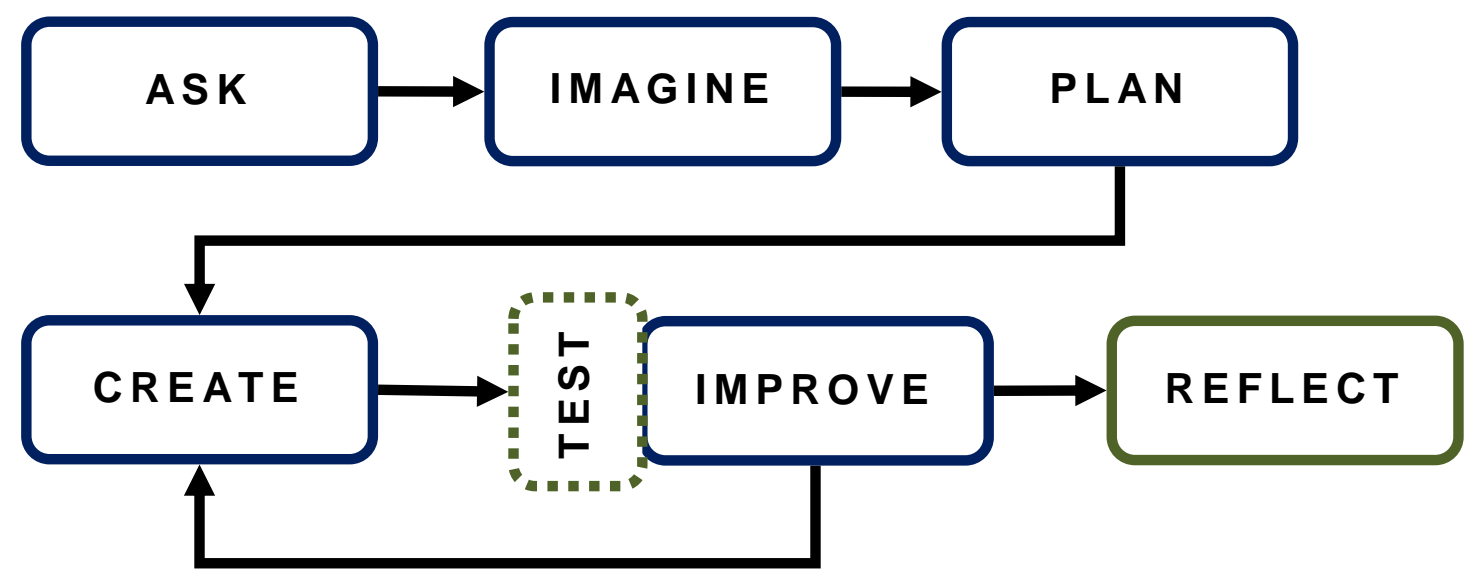

Figure 1: Engineering Design Process Presented for the Classroom

Engineering is Elementary ${ }^{\circledR}$ (EiE) presents an iterative process of Ask, Imagine, Plan, Create, and Improve. Ask is the act of gathering as much information about the problem (needed system) as possible. Imagine is a creative process of defining many ways of solving the problem at hand. Plan chooses a solution approach and assigns resources such as people, tools, and time to specific tasks. Sometimes, as a plan is fleshed out, more information about the need must be gathered or a different approach must be devised based upon resource availability. Once a plan is chosen, the Create process begins, which entails actually building the system. As the system is complex, a small portion of the total system is built at a time. Thus the last step, Improve, involves testing and adding to, or refining, the initial piece to increase/improve functionality. This continues until the total system fulfills its need.

It has been shown that the EiE process improves elementary students' ability to understand engineering concepts and the engineering design process ${ }^{10}$. Similarly, it has been shown that how these concepts are relayed to students plays an important role ${ }^{11}$. It was anticipated that the teachers would take the general process descriptions and likely make use of those directly in their classrooms when instructing their students. As such, the simplified terminology used by the EiE to describe the engineering design process was retained but modified to more applicable across the K-12 levels. The EiE process adequately captures the major steps that engineers go through with one exception, in the opinion of the authors. The process presented to the participants during the workshop includes a Reflect step after the system is completed (no 
further improvement is necessary). Reflection requires time be taken to consider what went well and what didn't during the entire course of the engineering process and why. This enables explicit lessons learned to be taken away from projects and, through sharing of these pros and cons, from others who very likely took a different approach to solving the same problem. Different engineering disciplines refer to this step using different terms. Software engineers, for example, may colloquially refer to this step as "post-mortem". Additionally, while testing is implicit in the EiE process, it has been made explicit here to stress its importance.

Similar to the EiE process, it must be emphasized that the revised process shown in Figure 1 is not rigid and that a teacher may employ a subset of the process steps in a project. EiE was devised for elementary grades and identifies the fact that sometimes students need to iterate or just go back a step. The process in Figure 1 explicitly shows steps that grades K-12 might manage and that teachers may emphasize. While the process shows going back to Create from Improve, if the current approach is failing then students should be encouraged to return to the Plan step instead or, perhaps, even going so far as to return to the Imagine step and rethinking an entirely new approach. If a teacher starts a project within the Imagine or latter steps, then all subsequent steps must be carefully devised and appropriately presented to the students. A key step to keep in mind and attempt to always include after a project is complete (regardless of other steps employed) is Reflect.

While Reflect may be considered a form of summative self-assessment, the process also entails formative self-assessment - usually at the end of each step. At the end of the Ask phase, a student should check that requirements are understood, that no discrepancies exist, and that no further questions about what the project should do currently exist. As the Imagine step completes, the student should have a set of potential solutions that seem feasible. If none seem possible to do or, in the process of discussing solutions a lot of questions arise about what is required, this is an indication that the student should return to the Ask phase of the process. It is very similar with Plan. As the Plan step finishes, the feasibility of executing the plan should be known. Is there enough material, time, and people? If not, then an earlier step should be revisited to select a different plan or find out more information. The most explicit form of self-assessment is the testing that is done between the Create and Improve steps. If a test fails, the student needs to explore why it failed and then devise approaches to fix the errors in the Improve step.

In the educational environment, teachers are locked within a rigid timeframe with a broad range of topics that are required to be taught. Time spent on a project often cannot be extended for students that require a longer period of time beyond the norm to complete. Thus, it is not practical for a teacher to grade novices using an iterative and incremental process like Engineering Design based solely on their ability to successfully complete a project within such an inflexible timeframe. As an alternative, teachers can assess whether students correctly use the process as a framework, including learning from mistakes. The emphasis here is on reinforcing 
the creative thinking skills and specific concepts; not to actually build the item used as a project vehicle (a paper tower, for example). Bailey and Szabo ${ }^{12}$ outlined several possibilities for those interested in assessing engineering design process knowledge. However, as these researchers concluded, the engineering design process is less concrete than many other engineering concepts and thus difficult to assess. To model some alternative assessment possibilities, this project used the following assessment approaches with the teachers during the summer institutes:

- teacher observation,

- participation in the discussion within the reflection portion of the project, and

- student engineering notebooks.

With the solving of a complex problem, it is often difficult to assess students based solely upon a summative assessment. Once activity has ended, a teacher can typically state whether or not the project met requirements. However, by that point, it is difficult to assess the approach that the students took to reach that point. Thus, formative assessment should be used at the end of each process step. It may even be necessary to provide students with the solution to earlier steps so that they can proceed with subsequent steps. A student who is unable to understand a problem well enough to imagine approaches to solving it would be unable to actually implement a solution. If, however, that student is then given a plan, it is possible that the student could implement the plan and, from that, begin to understand the project. The approach would depend upon the teacher's goals for the project.

summer workshop

The summer workshop consisted of sixty contact hours with the participants, spread out over ten days. The curriculum was constructed such that the entire group of teachers was provided instruction on some aspect of engineering or the engineering design process. Then, teams of teachers were presented with projects to solve using the concepts presented. There were nine projects in total. The projects were simple at first and did not require application of the entire engineering design process. Projects became more complex as the workshop progressed and concepts built upon one another, requiring full use of the presented process. Field trips comprised one-half of two days, and exposed the teachers to engineers within their working environment, reinforcing the concepts learned during discussions and projects. Additionally, projects employed varying tools and materials that were accessible to the teachers to maximize their applicability.

The learning experiences were designed on the premise that a defined process alone is not enough to enable understanding and application of sound engineering design principles. The workshop provided the context and tools that enabled the teachers to gain first-hand experience with the usage of the process, and to foster an environment in which the participants could envision applicability to their courses. In summary, it was desired that they experience 
application of the concepts in order to (a) better understand them and (b) be able to better conceive the potential application of the concepts to their own classroom. Loosely based upon Immersion Experience ${ }^{3,13}$, each day involved some class discussion on some aspect of engineering or the engineering design process. At the end of each discussion, the teachers worked in teams to solve some problem that related to the day's discussion. During the first day, participants were assigned to teams and provided engineering notebooks. Teams are important because an engineer rarely works alone. Thus, participants were given an overview of teaming approaches and instruction on how to conduct brainstorming sessions. At the end of each project, all teams met to discuss both team and individual lessons learned. They were also given direction on how to make copious use of their engineering notebooks. The notebooks were important because they capture an individual's and a team's ideas and allow the team to go back and recall what was decided and why_-improving both planning and execution. The teachers discovered that these notebooks became extremely useful as problems became more complex.

The engineering notebooks were bound composition books. Participants were first instructed to prepare their notebooks by titling the first page "Table of Contents" and using lowercase Roman numerals to paginate the first six pages. Both sides of each page were to be used, no blank pages were allowed. Starting with the seventh page, participants were instructed to paginate with Arabic numerals, starting with "1". Additionally, each of these pages was to be dated as content was added. Participants were instructed to record data from all phases of the engineering design process in their notebooks. Key requirements for the system being built, ideas and plans, designs, and a summary of test results were all to be captured. Essentially, the notebook was to be treated as a personal $\log$ as the participants worked at each project. Any piece of data that the participant felt would be frequently referred back to was to be entered into the Table of Contents with a descriptive title and the page number on which it would be found.

Each day consisted of one or more group discussions about an element of engineering and/or the engineering design process. Then, the group was broken into project teams. Project teams were set up such that each team consisted of three or four participant-teachers. For all projects, teams were allowed to self-manage specific team-member responsibilities. After each project, the group reformed to discuss the project results and applicability to various grade levels and course content. The topics and a description of each project and its purpose during each day follow:

\section{Day 1}

- Pre-test

- Program introduction

- Engineering Design Overview: Discussion on engineering, design, and some engineering disciplines. Discussion of a typical "real" engineering design process and transformation into the EiE-based process model to be used in the program. Also discussed teaming and 
brainstorming. Project introductory discussion on looking at how a complex system works and trying to understand it.

- Project 1: Decomposition

○ Description: LEGO ${ }^{\circledR}$ DUPLO $^{\circledR}$ blocks (Early Structures and Early Simple Machines sets) were used to create a Rube Goldberg machine ${ }^{14}$ out of simple pieces, using simple mechanical principles. Teams had to first analyze the system and describe the subsystem and subsystem elements in detail. Next, teams had to reproduce the functionality of the system using their own kits. Modifications were allowed as long as the functionality remained the same. Participants could interact with the instructor's model to familiarize themselves with the mechanics of each component. Participants were encouraged to ask how things worked and why specific elements of the system were set up as they were. In this way, the Plan step was minimized and so too was Create and Improve.

○ Purpose: Familiarize participants with how smaller systems work together to comprise larger systems and demonstrate that the creative thinking process could be applied at early stages of educational development. The project emphasized the Ask and Imagine steps. The Plan, Create, and Improve steps were minimized.

Day 2

- Simple Systems: Continued discussion on what a system is and familiarity with "basic" systems that have non-complex behavior and minimal component parts.

- Project 2: Simple Systems

○ Description: Teams were required to build two systems - a gear-spun top and a swing. Participants were required to first predict outcomes of how each system would behave under specific circumstances, then build the systems, and then test the systems - comparing results to predictions. Building sheets were provided, but no working models. Thus, participants had to rely upon prior knowledge to devise expected results. While Ask and Imagine were pretty well covered, participants were still encouraged to make sure that they thoroughly understood the problem before attempting to have the team work on creating the systems.

○ Purpose: Develop an understanding of how simple systems can be built from basic components and how different configurations impact system behavior. The Plan step was not challenging as the kits contained all necessary parts, which were identified in building instructions. The Create and Improve steps were exercised slightly as the teachers were required to change configurations of the systems in order to test and get the answers against which they could compare their predictions.

- Hierarchical Composition: Discussion on how simple systems can be combined to make a more complex system. Introduction to the concept of an interface and how complexity arises from interaction of component parts. 
- Project 3: Composition

- Description: Participants were required to build their own Rube Goldberg machine to move a toy car forward. Participants were provided instructions on how to build a plunger system that launched the car using force of hand. However, in this project, participants were not allowed to directly apply force to any component. They could only initiate motion of the first subsystem and allow another force, like gravity, to continue the interaction. Participants were required to make use of the systems from the previous project as part of the Rube Goldberg machine. This was also the first project for which teams were required to use the entire engineering design process.

- Purpose: Provide experience with taking predefined, simple systems and combining them to create a new, complex system. Thus, the project introduced to the concept of creating interaction between systems to implement a larger, more complex system. This project started with a lot of effort in the Imagine step of the process. Some came back to Ask for clarification of desired results after attempting to skip over it. It was the first project that really required the teachers to step through the process of imagining what could be, planning how to do it with available bricks, and then going through a number of iterations of Create and Improve.

Day 3

- Prototyping: Discussion on what prototyping is and why it is useful. Followed with a presentation that provided a high-level introduction to flight - how airplanes fly and how they move. Related this to paper airplanes.

- Project 4: Prototyping

○ Description: A paper airplane project in which participants were given requirements for airplane performance. Given a sample design and a discussion about paper airplane performance, participants had to design, build, and fly their own paper airplanes that met the performance criteria — maximum flight time, maximum distance, and accuracy. Teams had to use a full sheet of 8.5 " $\mathrm{x} 11$ " paper, and were allowed tape, staples, paper clips, and glue to modify the structure and behavior of the airplanes.

- Purpose: Exposed participants to building and testing prototypes to better understand unknown elements before building a final version. Teachers went through all steps of the process for this project. They were shown the performance of some completed models but could not duplicate them. However, they were encouraged to seek external sources of information, such as the Internet, in order to devise various approaches to solving the problem.

- Prototyping: Brief discussion on using prototyping within the development of a larger project.

- Project 5: Hierarchical generation and testing 
- Description: A paper towers project requiring participants to build the tallest paper tower possible using $8 \frac{1}{2}$ " $\times 11$ " sheets of paper and transparent adhesive tape. Towers were required to be free-standing. Teams were instructed to build prototypes of various potential structures with the paper to determine which might be best suited for a larger model.

- Purpose: This was the first project that required the participants to envision solutions from scratch. It also provided exposure to devising solutions within the confines of specific, restrictive requirements and limited materials. The intent of the hierarchical generation approach was to build prototypes and then build from the best prototype. All steps of the engineering design process were used. The project attempted to demonstrate that in imagining a solution, a "mini" engineering design process could be employed to rapidly build a rough solution (the prototype) and estimate its feasibility for building a full solution.

Day 4

- Tour: Group visited Melvin price Locks and Dam in East Alton, IL. Provided an opportunity to speak with engineers at their job sites about the kinds of problems that they solve on a daily basis. Discussed the types of education that were important for them.

Day 5

- Introduction to Software (Engineering): Discussion describing software and programming. Also, discussed software engineering and the creation of pseudocode.

- Project 6: Programming Logic

○ Description: Participants were required to write an algorithm to solve a software problem using English-like prose instead of a specific software language (this algorithm form is known in the software community as "pseudocode"). Using this approach, participants were encouraged to focus on solving software problems by thinking about what needed to be done in software rather than the how associated with a specific software language.

○ Purpose: Computers are ubiquitous in most systems today. However, many people (including teachers) have a fear of "messing with the software". It is important that teachers understand some of the basics of software systems and that software engineering is no different in its approach than other engineering disciplines. Additionally, this project provided a foundation for the robotics projects that required programming. This project focused on the Ask, Imagine, Plan steps towards successful creation of a software product.

- Introduction to Robotics: Provided an introduction to (autonomous) robots (what they are, where they are, and how they are created) and an introduction to the LEGO $^{\circledR}$ Mindstorms ${ }^{\circledR}$ graphical software development environment. 
- Project 7: Basic robots and programming

- Description: Participants were required to build a robot using the LEGO ${ }^{\circledR}$

Mindstorms ${ }^{\circledR}$ NXT 2.0 kit. Explicit building instructions were provided using a stepby-step electronic software tool. Instructions were also provided on how to program the robot using a visual development environment that came with the LEGO $^{\circledR}$ kits. Participants became familiar with making the robot move "blindly" using no external sensors. A project requiring them to program desired travel distance was also accomplished.

- Purpose: Provided experience with the hardware-software interface and, for most participants, their first experience programming. For some, this was even their first time using LEGO ${ }^{\circledR}$. The Create and Improve steps of the engineering design process were emphasized.

Day 6

- More Robotics: Discussion on sensors - what they are and a comparison to human senses. Introduced proprioception. Also discussed the hardware-software interface and related it back to the complexity issues that arise from interfaces that was discussed earlier in the program. Some discussion on robotics competitions for various grade levels.

- Project 8: Iterative software development

- Description: Participants modified the robot built previously with external sensors such as a light detector and a sound detector. Participants experimented with the sensors to gain familiarity with their responsiveness and making the robot perform distinct actions based upon sensor inputs. Robot tasks included starting/stopping upon hearing a sound and line following.

- Purpose: After completing the project, participants were familiar with enabling a robot to interact with its environment, and building simple software logic structures based upon sensor input. The Create and Improve steps of the engineering design process were emphasized.

Day 7

- Project 9: Final (Robotics) Project

○ Description: A final, multi-day project required the participants to design, build, and test a robot that could autonomously determine the size of a square enclosed by walls. The robot then had to drive in a circle that was circumscribed within the square. The first day emphasized the Ask, Imagine, and Plan steps of the engineering design process.

- Purpose: The project both incorporated all aspects of previous projects, required fullapplication of the engineering design process, and required participants to do additional research on their own to successfully plan and implement the project. 
Day 8

- Tour: The teachers were invited to tour the Boeing Corporation facility in St. Louis, MO. There they learned about Boeing's various products and spoke with engineers from various disciplines and of both male and female gender. The Teachers were able to ehar about the problems that the engineers worked on daily and discuss what it was that made each engineer interested in pursuing his/her discipline.

- Tour: The teachers visited an engineering school at a local university. There they spoke with a dean and multiple faculty about various engineering curriculum and the various jobs to which engineers from varied disciplines could look forward. This provided an opportunity to create a bridge between K-12 and college education.

Day 9

- Project 9: Final (Robotics) Project (continued)

○ Description: Teams continued to build their robots. This time, the emphasis was on the Create and Improve steps of the engineering design process. At the start of the day, the group met to reflect on the project thus far and share lessons learned.

Day 10

- Project 9 Presentations: Each team presented on their robot - the process application, the plan, the results, and a reflection of what did and did not work well.

- Course Preparation and Post-tests: The group met to review the entire program and discuss points that may and may not be applicable to their own classrooms. Preparations for fall lesson study were discussed and the post-tests were taken.

Some projects could be implemented within the teachers' classrooms and the materials chosen for the projects were selected for their accessibility to the participants. A number of projects made use of copy paper, construction paper, and transparent tape. Others made use of one or more LEGO $^{\circledR}$ kits. These kits were chosen for both their content and affordability within the budget provided to each teacher for purchase of curriculum materials as part of this research effort. However, projects were not specifically intended to be copy-paste instruments.

The discussions and projects were intended to enable teacher-participants to experience different elements of engineering and engineering design so that they might make an informed decision when choosing one or more of these elements (including materials) to incorporate into their curriculum. Furthermore, while projects such as simple structures may be too simple for grade 5 and the final project would be extremely challenging for grades $\mathrm{K}-3$, the intent of having teachers of all grade levels go through the progression of project complexity was to (1) provide a level of professional development that included a broad understanding of engineering and (2) enable the teachers to better understand how their curriculum might integrate with grades above and below their own. The choice of robotics was made due to the authors' own experiences with Science, Technology, Engineering, and Math (STEM) outreach — students and parents are 
energized by building robots and it appears to help keep students engaged in the learning environment. Additionally, the very nature of a robotic system supports a myriad of approaches to employing engineering design projects.

After each project, all participants met to reflect on the activities within the project. They discussed what went well and what went wrong. They also discussed how elements of a project might be applied at different grade levels, and what elements that they believed were inappropriate for specific situations. The teachers were encouraged to respond to their peers' concerns rather than have it be a researcher-led discussion.

In addition to projects, workshop participants were provided with two field trips to enable participant interaction with engineers in academia and in the field. The first field trip was to The Boeing Corporation in St. Louis, MO. Teachers heard from engineers (many of whom were minority individuals) in different engineering fields and they discussed what they believed to be important in K-12 education. Afterward, participants heard from an Associate Dean of a School of Engineering and one of its professors. There was a discussion about the many different engineering fields and, again, what the speakers believed was crucial to the success of K-12 students. The second field trip took participants to the Melvin Price Locks and Dam in East Alton, IL. There the teachers were exposed to working systems and were able to discuss with the Army Corps of Engineers the real-world complex problems that they had to solve on a day-today basis. A tour of the School of Engineering labs was also provided to expose participants to other problems being solved in laboratory environments.

Overall, the summer workshop presented engineering and engineering design principles to the teacher-participants and then allowed them to experience hands-on application of those principles. The Ask, Imagine, Plan, Create, Improve and Reflect engineering design steps were presented and applied during projects. While concepts built upon one another and became increasingly complex, workshop discussions before and after projects (during reflection periods) enabled participants to discuss the concepts being presented and their potential applications to varying grade levels. Projects served to ground concepts, and provide ideas for teacher classroom projects and material usage. These ideas were then made concrete and applied during the fall activities.

fall activities

The fall grant activities were designed to assist the teachers with the integration of engineering design into their science curriculum. Participants were allowed to purchase materials to encourage the implementation of engineering design concepts. Teachers from each district collaborated on the selection of materials most appropriate for their school settings. A list of suggested materials related to engineering design, including those used during the summer 
workshop, was provided. The professional learning communities established during the summer remained intact throughout the following fall in the form of lesson study groups. The idea was to continue the collaborative inquiry process among the teachers and promote the vertical integration of content within the school districts.

Lesson study is a method of teacher research that focuses on the development and refinement of lessons to provide instruction that reflects best practices in teaching. The lesson study process used for the purposes of this project was based upon steps outlined by Lewis and Hurd ${ }^{4}$ The basic steps included (1) planning the study, (2) teaching of the lesson, (3) post lesson discussion, and (4) final reflection. Previous research has indicated that lesson study and similar activities can have a positive impact on student learning ${ }^{15-16}$. The lesson study process fosters a deeper understanding of content, development of quality pedagogical practices and a focus on student learning ${ }^{4}$. It is not meant to assess an individual's teaching ability, but to investigate the instructional process and explore student understanding. With a focus on instructional improvement in mind, the teachers worked within their lesson study teams to design and implement a lesson related to engineering design.

At the beginning of the fall semester, all lesson study teams met as a group on a monthly basis. The steps of the lesson study process were outlined and explained thoroughly by two of the grant leaders. Video examples of a lesson study team were viewed and discussed to clarify the process. In the ensuing months, the teams identified a research theme, developed a lesson, planned the implementation and reflected on the process. One teacher from the group was chosen to teach the lesson and the rest observed and collected data. Videotaping was also completed by some of the groups and student artifacts were collected to provide further information. Members of the research team visited individual schools during lesson implementation as additional observers.

Throughout the process, lesson study teams reported their plans and progress to the whole group during monthly meetings. During these meetings, ideas were exchanged, problems were discussed, and innovative solutions were created. This provided each team with a source of support and encouragement and allowed them to take advantage of the collective wisdom and experience of all of the teachers involved. The fall semester concluded with final presentations by each team to the entire group summarizing their lesson study activities and future plans.

evaluation

The project hypothesis is that improved teacher content knowledge in the area of engineering design and technology related concepts and improved pedagogical skills will lead to higher teacher quality and greater student achievement. This hypothesis is being investigated under five research questions: 
1. (Professional development) Did the MASLI3-R project provide high-quality professional development activities?

2. (Teacher content knowledge) Did teachers who participated in the MASLI3-R project increase their content and conceptual knowledge of engineering design and technology related concepts?

3. (Teacher curriculum) Were teachers able to integrate scientifically-based instructional strategies into their classrooms including the use of lesson study?

4. (Student achievement) Did those students who took classes with MASLI3-R project teachers increase their understanding of the general curriculum through use of engineering design and technology-related concepts?

5. (Sustainability) Was there sufficient organizational support and change for the project to be sustained beyond the life of the grant award?

The evaluation of the project uses a quasi-experimental approach that follows two cohorts of teachers and their students from rural communities. Twenty-six teachers participated in the first cycle of activities. Twenty-five additional non- project teachers were purposely selected and assigned as a control group for the first cycle as a comparison for questions 3-5. Progress is reported using multiple measures that include:

- teacher content knowledge using a project designed exam,

- science teaching efficacy beliefs,

- teacher and classroom data using a science curriculum survey to gather information on such things as active learning, teacher preparedness, student reflection, and level of professional collegiality. The survey is derived from the Surveys of Enacted Curriculum developed jointly by Council of Chief State School Officers (CCSSO) and the Wisconsin Center for Education Research with funding from the National Science Foundation ${ }^{17}$,

- the quality of professional development activities based on teacher survey data,

- impact on students using state administered exams and project based content exams, and

- teacher work samples.

A summary of the evaluation approach and its expected outcomes for each research question are provided in the following table:

\begin{tabular}{|l|l|l|l|}
\hline $\begin{array}{l}\text { Evaluation } \\
\text { Question }\end{array}$ & Data Sources & $\begin{array}{l}\text { Anticipated Summative } \\
\text { Outcomes }\end{array}$ & Research Approach \\
\hline $\begin{array}{l}\text { Professional } \\
\text { development }\end{array}$ & $\begin{array}{l}\text { Project-developed } \\
\text { evaluation } \\
\text { instrument to gauge } \\
\text { project success; } \\
\text { including applicable }\end{array}$ & $\begin{array}{l}\text { Results provide direction to } \\
\text { project leaders for changes in } \\
\text { follow-up activities and } \\
\text { subsequent summer programs }\end{array}$ & $\begin{array}{l}\text { Project-developed } \\
\text { evaluation instrument } \\
\text { will be administered } \\
\text { four times-after } \\
\text { each summer session } \\
\text { and after each spring } \\
\text { school year session }\end{array}$ \\
\hline
\end{tabular}




\begin{tabular}{|c|c|c|c|}
\hline & $\begin{array}{l}\text { Illinois State Board } \\
\text { of Education } \\
\text { presentation } \\
\text { evaluation }\end{array}$ & $\begin{array}{l}\text { workshops support the } \\
\text { identified Illinois Learning } \\
\text { Standards } \\
85 \% \text { of teachers agree or } \\
\text { strongly agree that the } \\
\text { workshop met proposed } \\
\text { objectives } \\
85 \% \text { of teachers agree or } \\
\text { strongly agree that they were } \\
\text { satisfied with presenters and } \\
\text { presenter topics. }\end{array}$ & \\
\hline $\begin{array}{l}\text { Teacher } \\
\text { content } \\
\text { knowledge }\end{array}$ & $\begin{array}{l}\text { Project-identified } \\
\text { exam for the } \\
\text { summer workshop } \\
\text { that is specific to the } \\
\text { concepts and } \\
\text { pedagogy presented } \\
\text { at the workshops }\end{array}$ & $\begin{array}{l}\text { Project teachers demonstrate } \\
\text { significant gains on the content } \\
\text { exam over the period of the } \\
\text { project at the } p<0.01 \text { level } \\
\text { Project teachers demonstrate } \\
\text { significantly higher scores on } \\
\text { the content exams than the } \\
\text { control group on the post-test at } \\
\text { the } p<0.01 \text { level }\end{array}$ & $\begin{array}{l}\text { Project identified } \\
\text { exams administered } \\
\text { at the beginning and } \\
\text { end of the summer } \\
\text { workshops }\end{array}$ \\
\hline $\begin{array}{l}\text { Teacher } \\
\text { curriculum }\end{array}$ & $\begin{array}{l}\text { Curriculum survey } \\
\text { Science Teaching } \\
\text { Efficacy Belief } \\
\text { Instrument }\end{array}$ & $\begin{array}{l}\text { Teachers will demonstrate } \\
\text { significantly higher usage of } \\
\text { scientifically-based } \\
\text { instructional strategies when } \\
\text { compared to the control group } \\
\text { and their own pre-curriculum } \\
\text { survey results }\end{array}$ & $\begin{array}{l}\text { Project and control } \\
\text { teachers will } \\
\text { complete surveys } \\
\text { three times over the } \\
\text { course of the project. }\end{array}$ \\
\hline $\begin{array}{l}\text { Student } \\
\text { achievement }\end{array}$ & $\begin{array}{l}\text { Illinois Standards } \\
\text { Achievement Test } \\
\text { (ISAT) and Prairie } \\
\text { State Achievement } \\
\text { Examination (PSAE) } \\
\text { Project-identified } \\
\text { pre- and post-tests of } \\
\text { students in project } \\
\text { teachers' classes }\end{array}$ & $\begin{array}{l}\text { Project teachers' students will } \\
\text { have significantly higher overall } \\
\text { scores for the } 2013 \text { PSAE and } \\
\text { ISAT administrations when } \\
\text { compared with the } 2009 \text { and } \\
2010 \text { administrations } \\
\text { Students will demonstrate } \\
\text { significant gains at the } p<0.05 \\
\text { level for pre-test to post-test }\end{array}$ & $\begin{array}{l}\text { Gather math and } \\
\text { science ISAT and } \\
\text { PSAE scores } \\
\text { annually from } \\
\text { applicable classes for } \\
\text { comparison and } \\
\text { analysis } \\
\text { Teachers will test } \\
\text { students on relevant } \\
\text { concepts using the } \\
\text { NAEP questions at } \\
\text { the beginning and } \\
\text { end of each semester } \\
\text { (fall and spring) }\end{array}$ \\
\hline
\end{tabular}




\begin{tabular}{|l|l|l|l|}
\hline Sustainability & $\begin{array}{l}\text { Project funding and } \\
\text { planning }\end{array}$ & $\begin{array}{l}\text { Project will develop sufficient } \\
\text { inertia for equipment to be } \\
\text { continued to be used }\end{array}$ & $\begin{array}{l}\text { Identification of } \\
\text { summative outcomes } \\
\text { through access to } \\
\text { school district } \\
\text { administrative files }\end{array}$ \\
\hline
\end{tabular}

results

A summary of significant project findings are categorized and presented by research evaluation question.

Professional Development: Did the MASLI3-R project provide high-quality professional development activities?

Yes. The Overall Annual teacher Survey demonstrated very strong support for the project from the participants. Teachers identified several ways that the project has had a positive impact on their students, their districts, and their instruction. One hundred percent of the 24 responding teachers agreed (i.e., selected "Agree" or "Strongly Agree") that the project has increased rural K-12 teachers' understanding of engineering design and technology concepts. One hundred percent of the teachers also indicated that the project met their expectations, that they would recommend the program to other teachers, that they were confident that they could integrate engineering design and technology related concepts into their classrooms, that the project enhanced their ability to teach engineering design and technology related concepts to their students, and that, overall, the project has directly contributed to their ability to teach their students. Ninety-six percent of the teachers stated that they would do the project all over again if given the opportunity.

Teachers' Content Knowledge: Did teachers who participated in the MASLI3-R project increase their content and conceptual knowledge for engineering design and technology related concepts?

Yes. Project teachers had a significant increase on the project exam $(p=0.01)$. Control group teachers did not have a significant increase on the exam, which means that the changes could be attributed to project involvement.

Teacher Curriculum: Were teachers able to integrate scientifically-based instructional strategies into their classrooms including the use of lesson study?

Yes. There were two areas where there were significant changes on the curriculum survey and four significant belief changes on the Science Teaching Efficacy Belief survey. These changes were not experienced by the control group. Within the curriculum survey itself, 
sections on Teacher Preparedness and Scientific Thinking stood out. Teacher Preparedness as a whole increased significantly $(p=0.01)$, most notably in "Integrate science with other subjects" ( $p=0.006)$. While Scientific Thinking showed an increase, the $p$-value was only 0.067 for the general category. However, for "Make guesses, predictions, or hypotheses." the results showed a significant participant improvement $(p=0.005)$. On the Science Teaching Efficacy Belief survey, participants showed significant improvement on the following questions:

Question p-value

When a student does better that usual in science, it is often because the teacher 0.001 exerted a little extra effort.

$\begin{array}{ll}\text { I am continually finding better ways to teach science. } & 0.003\end{array}$

$\begin{array}{ll}\text { I know the steps necessary to teach science concepts effectively. } & 0.002\end{array}$

I am not very effective in monitoring science experiments. $\quad 0.005$

Student Achievement: Did students who took classes with MASLI3-R project teachers increase their content and conceptual knowledge for engineering design and technology-related concepts?

Unknown. There were significant increases $(p<0.001)$ on the project exam for 222 students in 12 teacher classes. There were no differences among the students on the Illinois Standards Achievement Test. That being said, these tests did not assess engineering design understanding directly and, as such, cannot be used to quantitatively answer the question. However, it is possible that changes seen in the test scores can be attributed to student use of the engineering design process as a tool for learning other curriculum.

Sustainability: Will there be sufficient organizational support and change for the project to be sustained beyond the life of the grant award?

This question still needs to be studied. The project team has worked to involve district and building administrators, who have been very positive about the project. However, the emphasis in curriculum, especially at lower grade levels, is not focused on science-based instruction. Still, teachers at lower grade levels have reported that using a project-based, engineering design approach has allowed them to garner the interest of typically poor performing students and students with learning disabilities.

conclusion

Providing engineering design instruction to K-12 grade teachers as professional development has yielded positive results. Teacher-participants finished the program feeling more confident and knowledgeable about technical topics. They also felt more confident about presenting these 
topics in an authoritative and organized fashion to their students. Furthermore, using the engineering design process (or elements thereof), the teachers have broadened the suite of tools from which they have to choose when providing instruction. Unfortunately, impact on the students who are taught using the engineering design process is harder to assess. There is feedback from teachers regarding increased engagement of students and positive experiences with otherwise disinterested students. Certainly, that is a good thing. However, there is no empirical evidence to show that the teachers can continue using the engineering design process to effectively teach core curriculum. Student Achievement and Sustainability are items that are better examined over longer periods.

Additionally, it is difficult to assess a significant increase in student learning based upon receiving instruction in engineering design from only one of many classes. The research team will examine the results of the twenty-five teachers who participated in the second cycle of activities. Their responses will be compared to those from twenty-seven additional non- project teachers were purposely selected and assigned as a control group for the second cycle. Consistency in improvement would be a positive indicator of an initial impact of our project efforts. However, it is likely that an additional study requiring a longer-term view of student performance in an environment that employs engineering design across many grade levels and/or courses would be required for adequate assessment of improvement in student achievement. Similarly, sustainability may be driven by changes in federal and state educational concepts, and by a repeated show of small successes on the parts of teachers who continue to use the engineering design approach in their curriculum. Again, this would require a different, longerterm study.

This project has also raised awareness of other issues not explicitly derived from survey results. First is the modification of the EiE process. Its original form has been accepted in some communities and demonstrated to be useful for its intended purpose - elementary educationprior to this project. While it's simplistic framework has proven useful for this project, the changes that were made - emphasizing Test and adding a Reflect step-were warranted. With these two items, the process has a broader applicability to various curriculum emphases throughout the K-12 grades. To that end, application of the engineering design process that we used as a tool requires levels of teacher directedness in its application.

Whether the teacher decides to employ the process as a tool for other curriculum or to teach the students about engineering design explicitly, the teacher must make a cognizant decision about integrating the process into the classroom and, perhaps, emphasizing or de-emphasizing specific steps dependent upon applicability of the step to the goal of the lesson. This requires the teacher to frame the problem such that the de-emphasized steps are part of the input into the problem, or define the output of the students' work such that it can be input into a predefined next step. The teacher should then devise assessment strategies for all steps within the process that the students 
are required to take. An approach similar to that taken for an Inquiry process may need to be devised $^{18}$. A ten-day program such as this is useful for introducing the teachers to the steps; however, it will take practice for a teacher to become familiar enough with the process to apply it well and make the aforementioned changes. Teacher communities have proven to be useful in this project for the purpose of sharing ideas, successes and failures, and reducing the time of the learning curve.

Also, as we look back at the questions we were using to assess the impact of our efforts, we realized that there is a shortcoming in standardized evaluation methods. New curriculum standards are moving toward the introduction and application of engineering design in the classrooms. However, current instruments to measure student knowledge of engineering design and its application are lacking. Development and testing of a rigorous, proven instrument was not within the scope of this project. However, it is something to be more carefully considered for future projects.

In summary, the first year of the project is perceived to have had some success based upon the self-reporting of the teacher-participant's impression of the impact that the project has had, and through the significant changes in specific areas between pre- and post-tests when compared to a control group. This data is supported by qualitative data (not presented above) such as stories of student activities that occurred in the classroom during the fall lesson study. While a lack of specific instrument for testing teacher and student engineering design knowledge was not available and, therefore, could not be applied, the science-based surveys provide insight into the potential effectiveness of engineering design process as a tool for teaching other curriculum. As stated above, combining the second year data with the first will provide additional information. However, a prolonged study on a larger sample population, with additional instrumentation, would be a logical next step to better understand the extent to which engineering design is useful in the classroom.

bibliography

1. National Research Council. (1996). National Science Education Standards. Washington, D.C.: National Academy Press.

2. Committee on Conceptual Framework for New Science Education Standards (2011)

3. Loucks-Horsley, et al. (2010). Designing Professional Development for Teachers of Science and Mathematics, 3rd ed. Thousand Oaks, CA: Corwin Press.

4. Lewis, C. and J. Hurd. (2011). Lesson Study Step by Step: How Teacher Learning Communities Improve Instruction. Portsmouth, NH: Heinemann. 
5. Partnership for 21st Century Skills (2011). A Framework for 21st Century Learning. http://www.p21.org. Last accessed January 2013.

6. Dym, C.L. (1994). Engineering Design: A Synthesis of Views. New York, NY: Cambridge University Press.

7. Ertas, A. and J.C. Jones. (1993). The Engineering Design Process. New York, NY: John Wiley \& Sons, Inc.

8. Horenstein, M.N. (2002). Design Concepts for Engineers, 2nd ed. Upper Saddle River, NJ: Prentice Hall.

9. Museum of Science, Boston (2004-2013). Engineering is Elementary. http://legacy.mos.org/eie/index.php. Last accessed January 2013.

10. Lachapelle, C.P. and C.M. Cunningham. (2007). "Engineering is elementary: Children's changing understanding of science and rngineering". In Proceedings of the 2007 American Society for Engineering Education Annual Conference \& Exposition. Honolulu, HI.

11. Davis, R.S., I.S. Ginns, and C.J. McRobbie. (2002). "Elementary school students' understanding of technology concepts". Journal of Technology Education. Vol. 14, No. 1: pp. 35-50.

12. Bailey, R. and Z. Szabo. (2006). "Assessing engineering design process knowledge". International Journal of Engineering Education. Vol. 22, No. 3: pp. 508-518.

13. Maine's Impact Study of Technology in Mathematics. (2000-2008). Immersion Experience. http://www2.edc.org/mistm/product/immersion.html. Last accessed January 2013.

14. Rube Goldberg Inc. (2013). Rube Goldberg. http://www.rubegoldberg.com/. Last accessed January 2013.

15. Waterman, S. (2011). Silicon Valley Mathematics Initiative: A Study of Lesson Study's Impact on Student Achievement. http://www.svmimac.org/lessonstudy.html. Last accessed January 2013.

16. Lewis, C., Perry, R., Hurd, J. \& O'Connell, M. P. (2006). "Lesson Study Comes of Age in North America." Phi Delta Kappan (December): 273-281.

17. Council of Chief State School Officers (CCSSO). (2012). Surveys of Enacted Curriculum (SEC). http://www.ccsso.org/Resources/Programs/Surveys_of_Enacted_Curriculum_(SEC) .html. Last accessed January 2013.

18. Center for Science, Mathematics, and Engineering Education. (2000). Inquiry and the National Science Education Standards: A Guide for Teaching and Learning. 